\title{
Evaluation of the Effectiveness of a Structured Diabetes Education Programme (CHOICE) on Clinical Outcomes for Adolescents with Type 1 Diabetes: A Randomised Controlled Trial
}

\author{
Vivien Coates ${ }^{1 *}$, David Chaney', Brendan Bunting ${ }^{2}$, Gillian W Shorter ${ }^{3}$, Mark Shevlin ${ }^{2}$, Andrea McDougall ${ }^{4}$ and Arlene Long ${ }^{5}$ \\ ${ }^{1}$ School of Nursing, University of Ulster, UK \\ ${ }^{2}$ School of Psychology, University of Ulster, UK \\ ${ }^{3}$ Bamford Centre for Mental Health and Wellbeing/ MRC All Ireland Hub for Trials Methodology Research, University of Ulster, UK \\ ${ }^{4}$ Royal Belfast Hospital for Sick Children, Belfast, UK \\ ${ }^{5}$ South Eastern Health and Social Care Trust, Ulster Hospital, Belfast, UK
}

\begin{abstract}
Aim: To evaluate the impact of the CHOICE structured diabetes education programme for adolescents with Type 1 diabetes on glycossylated haemoglobin, body mass index, episodes of hyper and hypoglycaemia and dietary adherence.

Methods: Multi-centred pragmatic randomised controlled trial (ISRCTN 13331558) across seven hospital sites in Northern Ireland, with 24 month follow-up. 135 adolescents between $13-19$ years with Type 1 diabetes were randomly assigned to structured diabetes education $(n=70)$ or control $(n=65)$. The intervention was designed to enable adolescents to adjust diet and insulin regimens, liberating their lifestyle to more closely match that of their peers without diabetes. It consisted of 12 hours education over 4 weeks, in 3 hourly interactive, group based sessions. Clinical outcome measures included glycossylated haemoglobin $(\mathrm{HbA} 1 \mathrm{c})$, body mass index, number of episodes of reported hyperglycaemia and hypoglycaemia and dietary adherence. Data were analysed on an intention to treat basis and was undertaken by a series of tests assessing both within and between group differences in means, variances and covariances.
\end{abstract}

Results: No significant difference between groups in $\mathrm{HbA1c}$ was noted despite the dietary liberation of the intervention group at 12 months however, there was a significant difference at 24 months (HbA1c) IG intervention $\%(\mathrm{mmol} / \mathrm{mol}) 9.53(81) \vee 8.99(75)$ control. There was no difference in BMI or in reported hyper or hypoglycaemic episodes.

Conclusion: Structured diabetes education (SDE) facilitated a more flexible diet, to which adolescents could adhere, with no detriment to glycaemic control at $12 \mathrm{~m}$, but not at $24 \mathrm{~m}$ post intervention.

Keywords: Structured diabetes education; Adolescents; Teenagers; Type 1 diabetes; Randomised controlled trial

\section{Introduction}

Managing Type 1 Diabetes Mellitus (Type $1 \mathrm{DM}$ ) in young people requires a number of self-care practices to achieve both optimal blood glucose control and maintain good quality of life. However, poor control is common in this age group and resultant long-term complications are well documented [1]. Consequently, life expectancy is reduced by up to 15 years in those with Type $1 \mathrm{DM}$ compared to healthy individuals of the same age [2].

To address the needs of adolescents, who may have poorer control in the teenage years $[3,4]$ a number of educational and psychosocial interventions have been developed. In reviewing these interventions, critiques have included poor methodological practice, insufficient follow up, or insufficient power to determine their efficacy $[5,6]$. International policy guidelines support the need for structured diabetes education (SDE) to be available to all young people with Type 1 DM [79], yet to date there exists no widely available SDE programme tailored specifically to the needs of adolescents within the United Kingdom (UK).

The aim was to develop a SDE programme (CHOICE) which acknowledges the challenges of adolescence and evaluate its impact on glycossylated haemoglobin, body mass index, episodes of hyper and hypoglycaemia and dietary adherence, quality of life, empowerment and self-management strategies in a multi-centred pragmatic randomised controlled trial across seven hospital sites in Northern Ireland. This paper presents the metabolic data from the study; psychological data will be presented in a separate paper. There were two main research questions; 1 . Does a structured education programme for adolescents improve glycaemic control and dietary adherence at 1, 3, 5, 12 and 24 months post intervention? 2. Does improved ability to manage diabetes in adolescence lead to weight gain? Although the inclusion of BMI amongst this patient group might be challenged, it was considered relevant due to pervading concern that a more liberal diet would lead to unacceptable weight gain.

*Corresponding author: Vivien E Coates, School of Nursing, University of Ulster Coleraine, Northern Ireland. / Western Health \& Social Care Trust, Londonderry UK, E-mail: ve.coates@ulster.ac.uk

Received June 26, 2013; Accepted August 07, 2013; Published August 13, 2013

Citation: Coates V, Chaney D, Bunting B, Shorter GW, Shevlin M, et al. (2013) Evaluation of the Effectiveness of a Structured Diabetes Education Programme (CHOICE) on Clinical Outcomes for Adolescents with Type 1 Diabetes: A Randomised Controlled Trial. J Diabetes Metab 4: 280. doi:10.4172/21556156.1000280

Copyright: @ 2013 Coates V, et al. This is an open-access article distributed under the terms of the Creative Commons Attribution License, which permits unrestricted use, distribution, and reproduction in any medium, provided the original author and source are credited. 
Citation: Coates V, Chaney D, Bunting B, Shorter GW, Shevlin M, et al. (2013) Evaluation of the Effectiveness of a Structured Diabetes Education Programme (CHOICE) on Clinical Outcomes for Adolescents with Type 1 Diabetes: A Randomised Controlled Trial. J Diabetes Metab 4 : 280. doi:10.4172/2155-6156.1000280

Page 2 of 7

\section{Patients and Methods}

\section{Participants}

Participants were recruited between January 2008 and November 2009 from seven acute hospitals in four Health \& Social Care Trusts in Northern Ireland. All were aged between 13-19 years and diagnosed with Type $1 \mathrm{DM}$ for a minimum of 12 months. Exclusion criteria were the presence of other medical conditions affecting diabetes management, learning disability, psychiatric admission in past 6 months, depression, documented substance abuse, self-harm or eating disorder. Both informed consent and assent were obtained prior to randomisation. Ethical approval was granted from the regional ethics committee (REC Reference number: 06/NIR01/114) and research governance was obtained from each of the Trusts. The trial was registered with the ISRCTN (number 13331558) and was adopted by the Northern Ireland Clinical Research Network.

\section{Intervention}

The structured diabetes educational programme was called CHOICE (Carbohydrate, Insulin, Collaborative Education) and focussed on insulin adjustment to liberate diet and lifestyle. The original programme was designed in Germany [10] and then adapted for UK use. CHOICE materials included a curriculum guide, food plates of standard meals, illustrations of individual portions to construct customised meals, flash cards to promote dialogue during teaching sessions and a flip chart to aid education. Participants retained an A5 binder to collate each of the 14 education units. An earlier phase of the study specifically tailored the programme to the adolescents' erratic lifestyle, accounting for pressures from friends and to be socially accepted [11]. Activities explored the interaction of carbohydrates and insulin requirements, timing of food and effects of exercise on blood glucose levels and insulin. Each session included an evening meal to give the participants supervised experience in assessing carbohydrate content and insulin requirements. Those aged 13-16 years were in separate programmes to those aged over 16 years with the exception of the final programme in which a wider span of age groups were included.

The CHOICE programme was delivered on four consecutive weekly sessions, for three hours in the evening. Sessions were attended by adolescents alone with the exception of one session on the final week 'Family / friends, lows and highs' in which assistance during times of erratic blood glucose control were discussed. Between sessions and at months 2, 4, \& 5, participants in the intervention group were texted by the Research Fellow (RF) to check on progress and encourage communication. Parents were invited to an information session one week before the programme to answer questions and illustrate how they could support their child. The programme was run 14 times, and always delivered by the RF (an experienced diabetes specialist nurse) and one of two experienced diabetes dieticians. The CHOICE programme, including a one month post intervention review, was delivered independently from the regular outpatient clinic. Subsequent reviews were undertaken within the adolescents' own diabetes clinic with all staff having received training in the CHOICE programme. The intervention was complete at month 5 (Figure 1).

\section{Routine care (Control)}

A protocol was agreed between all sites for routine care prior to commencing the study. This entailed a 3 monthly review at clinic during which time a problem solving approach was utilised by professionals to resolve immediate problems identified by the adolescent or their family.

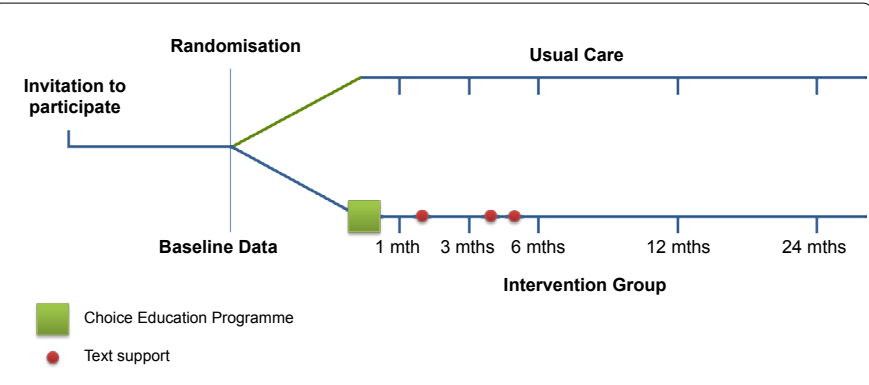

Figure 1: Design of the CHOICE Study.

\section{Randomisation}

A system of block randomisation was generated using blocks of eight by the trial statistician, stratified by location. After consent was obtained the RF telephoned an independent Research Secretary who informed the RF of the allocation to either the educational intervention or control.

\section{Sample size}

The intervention was delivered to 14 groups with a desired 10 individuals in each group. Five individuals were lost to the control group, leaving $\mathrm{N}=135$. For a $1 \%$ reduction in $\mathrm{HbA1c}$, where the standard deviation is set at 1.5 and with an intra-class correlation of 0.4 , the power to detect such an effect is in excess of 0.8 (alpha $0.05,2$-tailed). (In order to adjust for the effects of imputation, which optimises the sample size across the various points in time, the group sample size was reduced to 8 for the purpose of the current calculations, thus providing a lower bound estimate.)

\section{Primary and secondary outcome measures}

The primary outcome measure was $\mathrm{HbAlc}$ recorded at baseline, $1,3,6,12$ and 24 months. Secondary outcome measures including weight and height to allow estimation of body mass index (BMI) were recorded from patient records; the number of days per month in which hyperglycaemia and/or hypoglycaemia was experienced and adherence to diet were gathered by self-administered questionnaire. Dietary adherence was measured by means of the diet and adherence scale from the Diabetes Care Profile [12].

\section{Data collection and collation}

All baseline data were collected prior to randomisation. Capillary sampling was used to collect data relating to HbAlc and sent by each adolescent to a single laboratory. The HbAlc analyser used was DCCT aligned and conformed to the National Glycohemoglobin Standardization Program (NGSP). Questionnaires were completed by participants and mailed to the RF. Each adolescent received a $£ 10$ top up for their mobile phone upon receipt of their completed questionnaire. Data were collated, coded and analysed using SPSS (Version 17) [13] and MPlus [14].

\section{Statistical analysis}

Data analysis was undertaken by a series of tests assessing both within and between group differences in means, variances and covariances. These analyses were conducted in three steps:

Step 1: Test theoretical assumptions in relation to the control group such that the mean, variance and covariance should be equal across all time points (given they received no intervention). 
Citation: Coates V, Chaney D, Bunting B, Shorter GW, Shevlin M, et al. (2013) Evaluation of the Effectiveness of a Structured Diabetes Education Programme (CHOICE) on Clinical Outcomes for Adolescents with Type 1 Diabetes: A Randomised Controlled Trial. J Diabetes Metab 4: 280. doi:10.4172/2155-6156.1000280

Page 3 of 7

Step 2: Test theoretical assumptions in relation to the intervention group: whether the mean and variance were equal to the control group at baseline and from one month onward (testing whether the intervention affected the group post intervention).

Step 3: Test equality of variances, covariances and means across the groups (control and intervention).

This was an iterative procedure in which model fit was assessed and fixed relationships relaxed using modification indices (cut off point was a change in the modification indices of 5 or greater). All analyses were conducted using Maximum Likelihood (Robust) estimation, and this was used to estimate the model in the presence of missing data under the assumption of missing at random (MAR). This approach was taken in preference to ANOVA because it was important to examine variances and covariances in addition to the means. Further, it allowed us to relax a number of the statistical assumptions required in ANOVA, e.g., sphericity.

\section{Results}

From a target population of 400 eligible adolescents, 270 expressed an interest in the study, 159 agreed to participate of whom 135 returned consent forms. These were randomised to either intervention $(n=70)$ or control $(n=65)$.

\section{Demographic characteristics}

Although the study was open to all adolescents between the ages of 13 and 19 years of age, the majority, $76.1 \%(n=103)$ were aged 16 years or below. Duration of Type 1 DM ranged from 1-17 years. The mean baseline $\mathrm{HbAlc}$ of the entire sample was $8.9 \%(74 \mathrm{mmol} / \mathrm{mol})$. The majority of the sample, $75.5 \%(n=102)$ had a body mass index (BMI) of $25 \mathrm{~m}^{2}$ or less, placing them within the healthy range. However, $23 \%$ $(\mathrm{n}=31)$ had a BMI of above $25 \mathrm{~m}^{2}$ with $6.7 \%(\mathrm{n}=9)$ of these categorised as obese or morbidly obese. There were no significant differences between groups for any of the baseline data collected (Table 1).

\section{Attrition}

At 12 months HbA1c data were available for 100 (74\%) participants (57 Intervention; 43 Control) declining to 59 participants (31 Intervention; 28 Control) by 24 months. Analysis was undertaken to ascertain the predictability of missing data using $\mathrm{HbAlc}$ as the dependent variable tested against age, duration of diabetes, height, weight, BMI and each adolescents' perceived control of their diabetes. $\mathrm{HbAlc}$ was not predictive of missing data at any time point within the study.

Modelling means, variances and covariances in metabolic and clinical outcomes fit criteria for the final models for all outcomes are

\begin{tabular}{|l|c|c|c|c|}
\hline & \multicolumn{4}{|c|}{ Baseline statistics } \\
\hline Sex & \multicolumn{2}{|c|}{ Intervention } & \multicolumn{2}{c|}{ Control } \\
\hline & Male & 29 & Male & 34 \\
\hline & Female & 41 & Female & 31 \\
\hline Age (years) & Mean & SD & Mean & SD \\
\hline Duration (years) & 15.52 & 1.85 & 15.31 & 1.68 \\
\hline Baseline HbA1c \% (mmol/mol) & $6.73(72)$ & 1.54 & $9.04(75)$ & 1.42 \\
\hline BMI & 22.97 & 3.45 & 23.05 & 4.22 \\
\hline Weight & 63.19 & 11.52 & 63.08 & 12.32 \\
\hline Height & 1.66 & 0.10 & 1.65 & 0.09 \\
\hline \multicolumn{2}{|r|}{ Table $1:$ Baseline data. } \\
\end{tabular}

given in Table 2 and indicated good fit for all final models. Modelled mean $\mathrm{HbA} 1 \mathrm{c}$ levels were equivalent across control and intervention at all time points except at 24 months, where the $\mathrm{HbAlc}$ was higher for the intervention group (Table 3). A range of tests was also undertaken in relationship to the variances. These showed that variance was equivalent at baseline between control and intervention. Variances were equal between control and intervention groups at 1, 3 and 6 months. At 12 months there was more variability than at previous time points but this did not differ between control and intervention groups. The variance at 24 months was significantly larger in the intervention group. The sample means and variances for HbAlc were as follows: Intervention and control, mean (variance): Baseline, 8.73 (1.54) 9.04 (1.42); Month 1, 8.84 (1.57) 9.13 (1.41); Month 3, 8.98 (1.57) 9.14 (1.47); Month 6, 8.97 (1.68) 9.05 (1.32); Month 12, 8.90 (1.76) 8.96 (1.38).

The mean BMI was the same across intervention and control groups at baseline, 1, 3 and 6 months at $23.4 \mathrm{~m}^{2}$. This figure remained constant for the control group but there was a slight increase in the mean of the intervention group, $23.9 \mathrm{~m}^{2}$ at 12 months (Table $4 \mathrm{a}$ ). The variance at baseline in both groups was equal and lower at 1, 3, and 6 months (also equal in intervention and control group) suggesting participation in the trial was of benefit during the first six months. The variance in BMI at 12 months was significantly higher in the control group at 15.0 than in the intervention group 13.9. There was insufficient complete data for a robust 24 month analysis.

The approximate mean days of hyperglycaemic episodes was similar in both groups across time, at a mean of approximately six days, the only exception was a significantly higher number of days in which those in the intervention group experienced hyperglycaemia at 24 months (8 days) (Table $4 \mathrm{~b}$ ). The variance was highest at baseline (but equivalent between groups) with lower and equal variance from 1 month to 12 months (control) and 3 months to 12 months (intervention). The variance increased at 24 months, equal in both groups. There were no reported episodes of diabetic ketoacidosis during the study.

There were no differences between the control and intervention group in the number of days in which mild hypoglycaemia was experienced. However, there were some trends over time such that for both groups, there were on average 2.3 days at baseline, rising to 3.0 days at 1 month, and remaining at 2.6 days thereafter. Variances were broadly equivalent across all time points and in both groups. No significant difference was noted for reported episodes of severe hypoglycaemia between groups (Table 4c).

The mean score on the dietary adherence scale was equal at baseline for both intervention and control (6.9). However, this rose significantly, indicating better adherence at 1,3 and 6 months in the intervention group compared with the control group at 9.8, 8.3 and 7.8 before returning to baseline levels of 6.9 at 12 and 24 months (Table $4 \mathrm{~d}$ ). The modelled mean did not change over 24 months in the control group. Likewise, the variance did not differ from baseline to 6 months for either group. However, variance was highest at 12 months in the intervention group compared to the control group. Variance increased in the control group at 24 months, but reflected a small decrease at 24 months in the intervention group.

\section{Discussion}

The adolescents' baseline HbAlc, $8.9 \%$ (74 $\mathrm{mmol} / \mathrm{mol}$ ) was consistent with the National and European average reported elsewhere [15,16]. Adolescents allocated to the intervention group demonstrated no significant improvement in HbAlc at any time point 
Citation: Coates V, Chaney D, Bunting B, Shorter GW, Shevlin M, et al. (2013) Evaluation of the Effectiveness of a Structured Diabetes Education Programme (CHOICE) on Clinical Outcomes for Adolescents with Type 1 Diabetes: A Randomised Controlled Trial. J Diabetes Metab 4: 280. doi:10.4172/2155-6156.1000280

Page 4 of 7

\begin{tabular}{|c|c|c|c|c|c|c|c|}
\hline Outcome measure & Chi-square & df & $\mathbf{p}$ & CFI & TLI & RMSEA & $(90 \% \mathrm{Cl})$ \\
\hline Hba1c & 46.74 & 40.00 & 0.22 & 0.99 & 0.99 & 0.05 & $(0.00-0.10)$ \\
\hline BMI & 41.59 & 26 & 0.03 & 0.97 & 0.98 & 0.10 & $(0.03-0.15)$ \\
\hline Hyperglycaemic episodes & 38.95 & 42 & 0.61 & 1.00 & 1.00 & 0.00 & $(0.00-0.07)$ \\
\hline Hypoglycaemic episodes & 44.68 & 41 & 0.32 & 0.97 & 0.98 & 0.04 & $(0.00-0.09)$ \\
\hline Dietary adherence & 32.67 & 37 & 0.67 & 1.00 & 1.01 & 0.00 & $(0.00-0.07)$ \\
\hline
\end{tabular}

${ }^{1}$ Intermediate models are available on request from corresponding author

Table 2: Model fit for the final models each of the specified models with outcome variables of Hba1c, BMI, and Hyper/Hypoglycaemic episodes ${ }^{1}$.

\begin{tabular}{|c|c|c|c|c|c|c|c|}
\hline & & Baseline & 1 month & 3 months & 6 months & 12 months & 24 months \\
\hline \multirow[t]{2}{*}{ Control group } & $\begin{array}{c}\text { Mean }(95 \% \mathrm{Cl}) \% \\
\mathrm{mmol} / \mathrm{mol}\end{array}$ & $\begin{array}{c}8.99(8.75-9.23) \\
75(72-77)\end{array}$ & $\begin{array}{c}8.99(8.75-9.23) \\
75(72-77)\end{array}$ & $\begin{array}{c}8.99(8.75-9.23) \\
75(72-77)\end{array}$ & $\begin{array}{c}8.99(8.75-9.23) \\
75(72-77)\end{array}$ & $\begin{array}{c}8.99(8.75-9.23) \\
75(72-77)\end{array}$ & $\begin{array}{c}8.99(8.75-9.23) \\
75(72-77)\end{array}$ \\
\hline & Variance & 2.48 & 2.25 & 2.25 & 2.25 & 2.55 & 2.25 \\
\hline \multirow[t]{2}{*}{ Intervention group } & $\begin{array}{c}\text { Mean }(95 \% \mathrm{Cl}) \\
\% \\
\mathrm{mmol} / \mathrm{mol}\end{array}$ & $\begin{array}{c}8.99(8.75-9.23) \\
75(72-77)\end{array}$ & $\begin{array}{c}8.99(8.75-9.23) \\
75(72-77)\end{array}$ & $\begin{array}{c}8.99(8.75-9.23) \\
75(72-77)\end{array}$ & $\begin{array}{c}8.99(8.75-9.23) \\
75(72-77)\end{array}$ & $\begin{array}{c}8.99(8.75-9.23) \\
75(72-77)\end{array}$ & $\begin{array}{c}9.53(9.11-9.95) \\
81(76-85)\end{array}$ \\
\hline & Variance & 2.48 & 2.25 & 2.25 & 2.25 & 2.55 & 2.89 \\
\hline \multicolumn{8}{|c|}{ Intervention group } \\
\hline \multirow{3}{*}{$\begin{array}{l}\text { Covariances (and } \\
\text { correlations) }\end{array}$} & Baseline & & $2.07(0.88)$ & $1.78(0.75)$ & $1.82(0.77)$ & $1.87(0.74)$ & $1.99(0.74)$ \\
\hline & 1 month & $1.96(0.83)$ & & $1.96(0.87)$ & $1.96(0.87)$ & $1.90(0.79)$ & $1.96(0.77)$ \\
\hline & 3 months & $1.96(0.83)$ & $1.96(0.87)$ & & $1.96(0.87)$ & $1.96(0.82)$ & $1.96(0.77)$ \\
\hline \multirow[t]{3}{*}{ Control group } & 6 months & $1.96(0.83)$ & $1.96(0.87)$ & $1.96(0.87)$ & & $1.96(0.82)$ & $1.96(0.77)$ \\
\hline & 12 months & $1.96(0.78)$ & $1.79(0.75)$ & $1.96(0.82)$ & $1.96(0.82)$ & & $1.96(0.72)$ \\
\hline & 24 months & $1.96(0.83)$ & $1.96(0.87)$ & $1.96(0.87)$ & $1.96(0.87)$ & $1.96(0.82)$ & \\
\hline
\end{tabular}

Table 3: Population mean $(95 \% \mathrm{Cl})$, variances and covariances from the model with $\mathrm{Hba} 1 \mathrm{c}$ as primary outcome from baseline to 24 months.

\begin{tabular}{|c|c|c|c|c|c|c|}
\hline & & Baseline & 1 month & 3 months & 6 months & 12 months \\
\hline \multirow[t]{2}{*}{ Control group } & Mean $(95 \% \mathrm{Cl})$ & $23.41(22.79-24.03)$ & $23.41(22.79-24.03)$ & $23.41(22.79-24.03)$ & $23.41(22.79-24.03)$ & $23.41(22.79-24.03)$ \\
\hline & Variance & 14.55 & 13.49 & 13.49 & 13.49 & 15.03 \\
\hline \multirow{3}{*}{ Intervention group } & Mean $(95 \% \mathrm{Cl})$ & $23.41(22.79-24.03)$ & $23.41(22.79-24.03)$ & $23.41(22.79-24.03)$ & $23.41(22.79-24.03)$ & $23.76(23.07-24.44)$ \\
\hline & Variance & 14.55 & 13.49 & 13.49 & 13.49 & 13.86 \\
\hline & & & & & & Intervention group \\
\hline \multirow{5}{*}{ Covariances (and correlations) } & Baseline & & $13.47(0.96)$ & $13.22(0.94)$ & $12.74(0.91)$ & $12.87(0.91)$ \\
\hline & 1 month & $13.61(0.97)$ & & $12.92(0.96)$ & $12.92(0.96)$ & $12.92(0.94)$ \\
\hline & 3 months & $12.92(0.92)$ & $12.92(0.96)$ & & $12.92(0.96)$ & $12.92(0.94)$ \\
\hline & 6 months & $12.92(0.92)$ & $12.92(0.96)$ & $12.92(0.96)$ & & $13.11(0.96)$ \\
\hline & 12 months & $12.92(0.87)$ & $12.92(0.91)$ & $12.92(0.91)$ & $13.56(0.95)$ & \\
\hline
\end{tabular}

Table 4(a): Population mean $(95 \% \mathrm{Cl})$, variances and covariances from the model with $\mathrm{BMI}$ as outcome from baseline to 12 months.

\begin{tabular}{|c|c|c|c|c|c|c|c|}
\hline & & Baseline & 1 month & 3 months & 6 months & 12 months & 24 months \\
\hline \multirow[t]{2}{*}{ Control group } & Mean $(95 \% \mathrm{Cl})$ & $5.83(5.23-6.43)$ & $5.83(5.23-6.43)$ & $5.83(5.23-6.43)$ & $5.83(5.23-6.43)$ & $5.83(5.23-6.43)$ & $5.83(5.23-6.43)$ \\
\hline & Variance & 22.03 & 16.60 & 16.60 & 16.60 & 16.60 & 21.58 \\
\hline \multirow{3}{*}{ Intervention group } & Mean $(95 \% \mathrm{Cl})$ & $5.83(5.23-6.43)$ & $5.83(5.23-6.43)$ & $5.83(5.23-6.43)$ & $5.83(5.23-6.43)$ & $5.83(5.23-6.43)$ & $8.09(6.65-9.53)$ \\
\hline & Variance & 22.03 & 22.47 & 16.60 & 16.60 & 16.60 & 21.58 \\
\hline & & & & & & & Intervention group \\
\hline \multirow{3}{*}{ Covariances (and correlations) } & Baseline & & $10.68(0.48)$ & $7.70(0.40)$ & $6.88(0.36)$ & $8.83(0.46)$ & $3.80(0.17)$ \\
\hline & 1 month & $9.49(0.50)$ & & $9.49(0.49)$ & $9.49(0.49)$ & $9.49(0.49)$ & $9.49(0.43)$ \\
\hline & 3 months & $9.49(0.50)$ & $9.49(0.57)$ & & $9.49(0.57)$ & $9.49(0.57)$ & $9.49(0.50)$ \\
\hline \multirow{3}{*}{ Control group } & 6 months & $9.49(0.50)$ & $9.49(0.57)$ & $9.49(0.57)$ & & $9.49(0.57)$ & $9.49(0.50)$ \\
\hline & 12 months & $9.49(0.50)$ & $9.49(0.57)$ & $9.49(0.57)$ & $9.49(0.57)$ & & $9.49(0.50)$ \\
\hline & 24 months & $9.49(0.44)$ & $9.49(0.50)$ & $9.49(0.50)$ & $9.49(0.50)$ & $9.49(0.50)$ & \\
\hline
\end{tabular}

${ }^{1}$ Original coding of the hyperglycaemic episodes was grouped to assist adolescents to estimate their episodes. The midpoint of the range was taken to ensure more meaningful population mean values such that " $1-3$ days" $=2$; "4- 6 days" $=5$, "7-12 days" $=10$ " 12 or more"=13

Table 4(b): Population mean $(95 \% \mathrm{Cl})$, variances and covariances from the model of hyperglycaemic episodes as outcome from baseline to 24 months ${ }^{1}$.

post intervention when compared with those in the control group. However, it could be argued that despite a much more liberal diet in which adolescents could adjust their insulin for their dietary intake, those in the intervention group did not experience deterioration in HbA1c nor any weight gain during the first 12 months of follow-up. The 24 month data demonstrates a significant rise in HbAlc amongst the intervention group and increased variance of results. The results from the first year of the study offer tentative evidence to support the effectiveness of structured education programmes amongst adolescents with Type $1 \mathrm{DM}$, thereafter they are less supportive. Based on these results modifications have been made to the programme and further evaluation is being carried out across Northern Ireland and with 
Citation: Coates V, Chaney D, Bunting B, Shorter GW, Shevlin M, et al. (2013) Evaluation of the Effectiveness of a Structured Diabetes Education Programme (CHOICE) on Clinical Outcomes for Adolescents with Type 1 Diabetes: A Randomised Controlled Trial. J Diabetes Metab 4: 280. doi:10.4172/2155-6156.1000280

Page 5 of 7

\begin{tabular}{|c|c|c|c|c|c|c|c|}
\hline & & Baseline & 1 month & 3 months & 6 months & 12 months & 24 months \\
\hline \multirow[t]{2}{*}{ Control group } & Mean $(95 \% \mathrm{Cl})$ & $2.33(2.07-2.59)$ & $3.04(2.82-3.25)$ & $2.61(2.44-2.78)$ & $2.61(2.44-2.78)$ & $2.61(2.44-2.78)$ & $2.61(2.44-2.78)$ \\
\hline & Variance & 1.61 & 1.60 & 1.60 & 1.60 & 1.60 & 1.60 \\
\hline \multirow{3}{*}{ Intervention group } & Mean $(95 \% \mathrm{Cl})$ & $2.33(2.07-2.59)$ & $3.04(2.82-3.25)$ & $2.61(2.44-2.78)$ & $2.61(2.44-2.78)$ & $2.61(2.44-2.78)$ & $2.61(2.44-2.78)$ \\
\hline & Variance & 1.60 & 1.60 & 1.60 & 1.60 & 1.60 & 1.60 \\
\hline & & & & & & & Intervention group \\
\hline \multirow{3}{*}{$\begin{array}{l}\text { Covariances (and } \\
\text { correlations) }\end{array}$} & Baseline & & $0.66(0.41)$ & $0.11(0.07)$ & $0.02(0.01)$ & $0.76(0.48)$ & $0.29(0.18)$ \\
\hline & 1 month & $0.57(0.36)$ & & $0.57(0.36)$ & $0.57(0.36)$ & $0.57(0.36)$ & $0.57(0.36)$ \\
\hline & 3 months & $0.11(0.07)$ & $0.57(0.36)$ & & $0.57(0.36)$ & $0.57(0.36)$ & $0.57(0.36)$ \\
\hline \multirow{3}{*}{ Control group } & 6 months & $0.57(0.36)$ & $0.57(0.36)$ & $0.57(0.36)$ & & $0.57(0.36)$ & $0.57(0.36)$ \\
\hline & 12 months & $0.57(0.36)$ & $0.57(0.36)$ & $0.57(0.36)$ & $0.57(0.36)$ & & $0.71(0.44)$ \\
\hline & 24 months & $0.57(0.36)$ & $0.57(0.36)$ & $0.57(0.36)$ & $0.57(0.36)$ & $0.97(0.61)$ & \\
\hline
\end{tabular}

Table 4(c): Population mean $(95 \% \mathrm{Cl})$, variances and covariances from the model with hypoglycaemic episodes as outcome from baseline to 24 months

\begin{tabular}{|c|c|c|c|c|c|c|c|}
\hline \multicolumn{2}{|l|}{ Dietary adherence } & Baseline & 1 month & 3 months & 6 months & 12 months & 24 months \\
\hline \multirow[t]{2}{*}{ Control group } & Mean $(95 \% \mathrm{Cl})$ & $6.91(6.51-7.32)$ & $6.91(6.51-7.32)$ & $6.91(6.51-7.32)$ & $6.91(6.51-7.32)$ & $6.91(6.51-7.32)$ & $6.91(6.51-7.32)$ \\
\hline & Variance & 7.93 & 7.93 & 7.93 & 7.93 & 7.93 & 11.57 \\
\hline \multirow{3}{*}{ Intervention group } & Mean $(95 \% \mathrm{Cl})$ & $6.91(6.51-7.32)$ & $8.85(8.25-7.32)$ & $8.33(7.67-8.99)$ & $7.83(7.13-8.53)$ & $6.91(6.51-7.32)$ & $6.91(6.51-7.32)$ \\
\hline & Variance & 7.93 & 7.93 & 7.93 & 7.93 & 12.01 & 11.57 \\
\hline & & & & & & & Intervention group \\
\hline \multirow{6}{*}{ Covariances (and correlations) } & Baseline & & $2.66(0.34)$ & $3.51(0.44)$ & $3.98(0.50)$ & $3.38(0.35)$ & $3.28(0.34)$ \\
\hline & 1 month & $6.45(0.81)$ & & $4.84(0.61)$ & $4.84(0.61)$ & $4.84(0.50)$ & $4.84(0.51)$ \\
\hline & 3 months & $4.84(0.61)$ & $4.84(0.61)$ & & $4.84(0.61)$ & $4.84(0.50)$ & $4.84(0.51)$ \\
\hline & 6 months & $3.20(0.47)$ & $2.74(0.35)$ & $4.84(0.61)$ & & $4.84(0.50)$ & $4.84(0.51)$ \\
\hline & 12 months & $4.84(0.61)$ & $4.84(0.61)$ & $3.47(0.44)$ & $4.84(0.61)$ & & $4.84(0.41)$ \\
\hline & 24 months & $4.84(0.51)$ & $4.84(0.51)$ & $4.84(0.51)$ & $4.84(0.51)$ & $4.84(0.51)$ & \\
\hline
\end{tabular}

Table 4(d): Population mean $(95 \% \mathrm{Cl})$, variances and covariances from the model with dietary adherence as outcome from baseline to 24 months.

the Southern Irish border counties. Given the prominence of SDE as an effective means of improving glycaemic control for all people with diabetes $[17,18]$ it is disappointing that a significant reduction in HbAlc could not be achieved. Nevertheless, the importance of publishing 'non-significant' results is currently emphasised in order to make the full field of evidence available [19].

While lack of improvement in HbAlc might simply be that the CHOICE programme is not effective, in view of the persistent poor glycaemic control reported globally $[15,16,20]$ there is a need to consider other possible influences that may impede adolescents from achieving specified targets. One area that has been highlighted is the influence of growth hormone on insulin sensitivity during puberty. There is increasing recognition that normal adolescent development may in itself be a barrier to optimal glycaemic control [21,22].

The programme, designed with input from young people, was to be transferable into routine practice. On reflection it may not be possible to cover such a complex subject, with adolescents, with widely varying numeracy and literacy ability, in such a relatively short time (12 hours). The need for further support following the four week structured programme was apparent as several positive effects (eg dietary adherence) deteriorated over time post intervention and particularly at 24 months. Cooper et al. (2008) also reported that diabetes education cannot be expected to have lasting effects on glycaemic control [23]. This suggests that for adolescents it is helpful to 'top up' the intervention over time.

Despite their newly instructed ability to match insulin with carbohydrate and thus engage in greater dietary freedom, there was only a slight increase in BMI among those in the intervention group and this difference of less than $1 \mathrm{~m}^{2}$, is unlikely to be clinically relevant. This is contrary to the belief of many professionals who are concerned that liberalising the diet will lead to significant weight gain. The absence of increased weight is further supported by the dietary behaviours of those within the intervention group who reported significantly higher dietary adherence for months 1,3 and 6 .

Only four participants randomised to the education arm of the study failed to complete the SDE programme. This suggests that once adolescents decide to engage in diabetes education the majority will choose to remain until completion. Thus every effort must be made during this time to maintain interest and develop a relationship that can be carried forward into routine clinical consultations.

The engagement of adolescents in SDE programmes only after they have been diagnosed for a period of at least one year should be reviewed. Education is seen by professionals as a fundamental part of diabetes care $[17,18]$. Therefore diabetes education needs to be awarded priority after diagnosis. The Berger programme on which both CHOICE and DAFNE have been based is normally delivered within Germany immediately after diagnosis [10]. Thus a move to deliver SDE shortly after diagnosis in the UK would be consistent with the programme's original design. It is also recommended that adolescents and their families be prescribed an education programme in a manner similar to the prescription of insulin or blood glucose monitoring equipment. Delivery of SDE at this early stage will negate the difficulties associated with trying to change established behaviour at 1 year post diagnosis. On the other hand this will make structured group education at local level very difficult to predict and organise.

\section{Parental involvement}

The role of parents in adolescent diabetes management is complex and requires a balance of involvement. Evidence suggests that parental involvement increases adherence and glycaemic control during adolescence [24-26]. However the amount of involvement is a key factor, with higher parental involvement often viewed as rigid 
Citation: Coates V, Chaney D, Bunting B, Shorter GW, Shevlin M, et al. (2013) Evaluation of the Effectiveness of a Structured Diabetes Education Programme (CHOICE) on Clinical Outcomes for Adolescents with Type 1 Diabetes: A Randomised Controlled Trial. J Diabetes Metab 4 : 280. doi:10.4172/2155-6156.1000280

and controlling, inhibiting the development of autonomy among some adolescents [25]. Murphy et al. (2007) [27] have highlighted the difficulties associated with parental involvement, with fathers much harder to engage in SDE programmes. Parental involvement does not always equate to improved outcomes [28] hence a balance of involvement needs to be found.

\section{Limitations}

From a population of 400 eligible adolescents only 135 participated in the trial. The reasons why so many declined was not known as many gave no reason. Attrition over the two years of the follow-up period meant that there was inadequate data for robust analysis of BMI at 24 months. Attrition in the second year of the study was higher than anticipated. The trial was intentionally designed with no research input during year 2, to more closely emulate routine practice. These results indicate that ongoing support /input is required following the educational intervention. A more substantial financial incentive may have been helpful in retaining participants from both arms of the trial to the 24 month endpoint.

It is important that no severe acute complications were reported.. These episodes of hyper /hypo glycaemia were to be documented in the first instance by the participants based on items from a previously designed questionnaire [12] however it is acknowledged that relying on self-reported episodes of hyper and hypoglycaemia may be considered a limitation.

Identical values indicate that the parameters have been constrained to be equal, such that they do not significantly differ from one another.

\section{Conclusion}

Optimal glycaemic control remains difficult within the adolescent population. However adolescents were willing to engage with a structured education programme designed to improve diabetes control whilst enabling them to be more like their peers. This study highlights the inadequacy of a single intervention and the need for ongoing structured educational support. A 12 hour curriculum may not allow sufficient time to master the complexities of insulin adjustment in adolescents. A programme in which the SDE is provided by the regular diabetes team is thought more likely to succeed as there will be greater opportunity for educational follow-up. Despite the initial low uptake of the CHOICE programme, once the adolescents committed to it they remained fully engaged even when such engagement involved adherence to a complex regimen of insulin and dietary adjustment. Liberation of diet did not lead to poorer glycaemic control or significant weight gain during the first year post intervention. These initial results indicate that there are benefits to be gained for young people with type 1 diabetes engaging in the CHOICE programme. Drawing upon the strengths of the programme and from experience and lessons learnt when conducting the trial, the CHOICE programme has been modified and is currently undergoing further evaluation.

\section{Sources of Funding} UK.

Diabetes UK; Public Health Agency, R\&D Division, Belfast; Roche Diagnostics,

\section{References}

1. Diabetes Control and Complications Trial Research Group (1993) The effect of intensive treatment of diabetes on the development and progression of long-term complications in insulin-dependent diabetes mellitus. The Diabetes Control and Complications Trial Research Group. N Engl J Med 329: 977-986.

2. National Institute of Clinical Excellence (2009) Diabetes Update 2009. [www dh.gov.uk/en/Healthcare/Longtermconditions/Vascular/Diabetes/DH-074]
3. Greening L, Stoppelbein L, Konishi C, Jordan SS, Moll G (2007) Child routines and youths' adherence to treatment for type 1 diabetes. J Pediatr Psychol 32: 437-447.

4. Leonard BJ, Jang YP, Savik K, Plumbo MA (2005) Adolescents with type 1 diabetes: family functioning and metabolic control. J Fam Nurs 11: 102-121.

5. Couch R, Jetha M, Dryden DM, Hooton N, Liang Y, et al. (2008) Diabetes Education for Children with Type 1 Diabetes Mellitus and their Families. 166. Edmonton Canada: Agency for Healthcare Research and Quality.

6. Murphy HR, Rayman G, Skinner TC (2006) Psycho-educational interventions for children and young people with Type 1 diabetes. Diabet Med 23: 935-943.

7. Swift PG (2009) Diabetes education in children and adolescents. Pediatr Diabetes 10 Suppl 12: 51-57.

8. Lange K, Sassmann H, von Schütz W, Kordonouri O, Danne T (2007) Prerequisites for age-appropriate education in type 1 diabetes: a mode programme for paediatric diabetes education in Germany. Pediatr Diabetes 8 Suppl 6: 63-71.

9. Department of Health and Diabetes UK (2005) Structured patient education in diabetes: Report from the Patient Education Working Group.

10. Muhlhauser I, Bruckner I, Berger M, Cheta D, Jorgens V, et al. (1987) Evaluation of an intensified insulin treatment and teaching programme as routine management of type 1 (insulin-dependent) diabetes. The BucharestDüsseldorf Study. Diabetologia 30: 681-690.

11. Chaney D, Coates V, Shevlin M, Carson D, McDougall A, et al. (2012) Diabetes education: what do adolescents want? J Clin Nurs 21: 216-223.

12. Fitzgerald JT, Davis WK, Connell CM, Hess GE, Funnell MM, et al. (1996) Development and validation of the Diabetes Care Profile. Eval Health Prof 19 208-230.

13. SPSS Inc. Released 2008. SPSS Statistics for Windows, Version 17.0 Chicago: SPSS Inc.

14. MPLUS (Version 6.11). [Computer Software]. Los Angeles, CA: Muthén \& Muthén.

15. National Diabetes Audit (2010) National diabetes audit executive summary 2008-2009. London: The NHS Information Centre.

16. de Beaufort CE, Swift PG, Skinner CT, Aanstoot HJ, Aman J, et al. (2007) Continuing stability of center differences in pediatric diabetes care: do advances in diabetes treatment improve outcome? The Hvidoere Study Group on Childhood Diabetes. Diabetes Care 30: 2245-2250.

17. Department of Health (2004) Choosing health? Making healthy choices easier

18. National Institute for Clinical Excellence (2003) Guidance on the use of patienteducation models for diabetes.

19. Dickersin K, Chalmers I (2011) Recognizing, investigating and dealing with incomplete and biased reporting of clinical research: from Francis Bacon to the WHO. J R Soc Med 104: 532-538.

20. Cardwell CR, Patterson CC, Allen M, Carson DJ; Northern Ireland Paediatric Diabetes Study Group (2005) Diabetes care provision and glycaemic control in Northern Ireland: a UK regional audit. Arch Dis Child 90: 468-473.

21. Szadkowska A, Pietrzak I, Mianowska B, Bodalska-Lipinska J, Keenan HA, et al. (2008) Insulin sensitivity in Type 1 diabetic children and adolescents. Diabet Med 25: 282-288.

22. Swan KL, Weinzimer SA, Dziura JD, Steil GM, Voskanyan GR, et al. (2008) Effect of puberty on the pharmacodynamic and pharmacokinetic properties of insulin pump therapy in youth with type 1 diabetes. Diabetes Care 31: 44-46.

23. Cooper H, Booth K, Gill G (2008) A trial of empowerment-based education in type 2 diabetes--global rather than glycaemic benefits. Diabetes Res Clin Pract 82: 165-171.

24. Viklund G, Ortqvist E, Wikblad K (2007) Assessment of an empowerment education programme. A randomized study in teenagers with diabetes. Diabet Med 24: 550-556.

25. Anderson BJ, Svoren B, Laffel L (2007) Initiatives to promote effective self-care skills in children and adolescents with diabetes mellitus. Disease Management \& Health Outcomes 15: 101-108.

26. Palmer DL, Berg CA, Wiebe DJ, Beveridge RM, Korbel CD, et al. (2004) The role of autonomy and pubertal status in understanding age differences in 
Citation: Coates V, Chaney D, Bunting B, Shorter GW, Shevlin M, et al. (2013) Evaluation of the Effectiveness of a Structured Diabetes Education Programme (CHOICE) on Clinical Outcomes for Adolescents with Type 1 Diabetes: A Randomised Controlled Trial. J Diabetes Metab 4: 280. doi:10.4172/2155-6156.1000280

Page 7 of 7

maternal involvement in diabetes responsibility across adolescence. J Pediatr Psychol 29: 35-46.

27. Murphy HR, Wadham C, Rayman G, Skinner TC (2007) Approaches to integrating paediatric diabetes care and structured education: experiences from the Families, Adolescents, and Children's Teamwork Study (FACTS). Diabet Med 24: 1261-1268.

28. Hanna KM, Guthrie D (2003) Adolescents' behavioral autonomy related to diabetes management and adolescent activities/rules. Diabetes Educ 29: 283 291. 